This article was downloaded by:[University of Lancaster]

On: 9 January 2007

[University of Lancaster]

Access Details: [subscription number 731661109]

Publisher: Taylor \& Francis

Informa Ltd Registered in England and Wales Registered Number: 1072954

Registered office: Mortimer House, 37-41 Mortimer Street, London W1T 3JH, UK

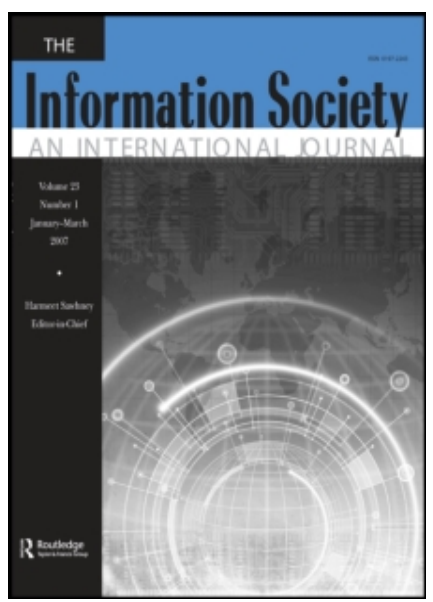

\title{
The Information Society
}

An International Journal

Publication details, including instructions for authors and subscription

information: http://www.informaworld.com/smpp/title content=t713669588

Practice-Based Design of Information Systems: Notes from the Hyperdeveloped World

Lucy A. Suchman

Online Publication Date: 01 March 2002

To link to this article: DOI: $10.1080 / 01972240290075066$

URL: http://dx.doi.org/10.1080/01972240290075066

Full terms and conditions of use: http://www.informaworld.com/terms-and-conditions-of-access.pdf

This article maybe used for research, teaching and private study purposes. Any substantial or systematic reproduction, re-distribution, re-selling, loan or sub-licensing, systematic supply or distribution in any form to anyone is expressly forbidden.

The publisher does not give any warranty express or implied or make any representation that the contents will be complete or accurate or up to date. The accuracy of any instructions, formulae and drug doses should be independently verified with primary sources. The publisher shall not be liable for any loss, actions, claims, proceedings, demand or costs or damages whatsoever or howsoever caused arising directly or indirectly in connection with or arising out of the use of this material.

(c) Taylor and Francis 2007 


\title{
Practice-Based Design of Information Systems: Notes from the Hyperdeveloped World
}

\author{
Lucy A. Suchman
}

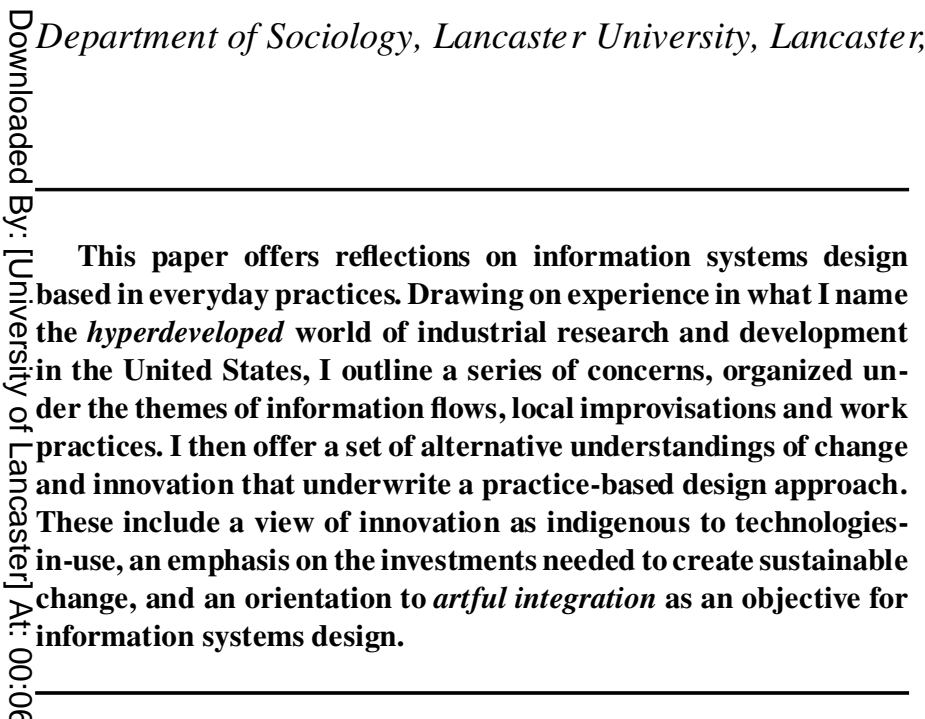

GKeywords practice, ethnography, research and development, design @) and use, innovation

Having spent the past 20 years working at the center of what I can only describe as the hyper-developed world, I am in some obvious ways uniquely unqualified to be writing on the topic of information and communications technologies (ICT) in developing countries. In reflecting on what might be relevant from my own experience, however, I take my lead from the conference themes of the 2000 Conference of the IFIP 9.4 Working Group on Social Implications of Computers in Developing Countries. First, the conference themes point to the figure of information flows, what science and technology theorist Donna Haraway (1991) called, with some irony, the "circuits" through which what we know about computer systems (and about many other things), as well as how we know it, gets configured up and moved around the globe. What interests Haraway are the ways in which those

Received 15 November 2000; accepted 15 July 2001.

Address correspondence to Lucy A. Suchman, Professor, Centre for Science Studies, Department of Sociology, Lancaster University, Cartmel College, Lancaster LA1 4YL, United Kingdom. E-mail: 1.suchman@lancaster.ac.uk

flows work to define what are the legitimate discourses, and thereby in some real sense the condition s of possibility, for imagining, designing, and developing new information technologies.

One obvious concern here is the asymmetrical directionality of those flows, insofar as those in the hyperdeveloped countries maintain a disproportionate hold over the distribution of at least computer-based information technologies, and remain largely ignorant of activities elsewhere. Those in the so-called developing countries, meanwhile, are inundated with the products, processes, and propagand a generated in the commercial, educational, and governmental centers of the high-tech North. So one question that could animate our projects is: What are the opportunitie s to interrupt these asymmetric flows and redirect them? What alternative configurations of technologie s and practices might then be possible? And perhaps a prior question: In what ways are these flows already, in fact, more multidirectional than the mainstream discourse of globalizing information systems would suggest?

Secondly, the conference themes orient us to local improvisations, which I take to be the means by which anything - technological systems, organizational forms, everyday projects - are made to work. Here I want to underscore the extent to which this is the case not only for the export of solutions from the developed to the developing world, but from any site of technology production to other sites of technologies-in-use. The greater the distancegeographical, economic, cultural, experiential the greater the need for reworking is likely to be. But some amount of appropriation into local circumstances will always be required. The question is not whether that work will need to be done, but with what ease or difficulty.

Local improvisation, moreover, is not just a matter of receiving something already made and incorporating it into a new site of use. Rather, improvisational activities are the generative practices out of which new technologies are made. Daniel Miller and Donald Slater (2000) make this point strongly in their recent book, The Internet: An Ethnographic Approach. In their words, the book, which 
explores the question of local improvisation s in the case of Trinidad,

is not a case study of the localisation or the appropriation of a global form by local cultural concerns. It is not about domesticating a technology.... Indeed the significance of studying the Internet is the degree to which it transcends dualisms such as local against global. It forces us to acknowledge a more complex dialectic through which specificity is a product of generality and vice versa. (p. 7)

Local Trinidadians, they insist, do not meet a global InOornet. Rather, the Internet just is the specific practices Jof groups like those Trinidadians that they describeonothing more, nothing less. To say the latter is to leave ळopen the question of local and global, at least as anything wppreconceived before our investigation begins. Both locality and globalness are effects achieved in and through the discourse and practices of ICT. Just how they are achieved is an empirical question, and one about which, they sug-

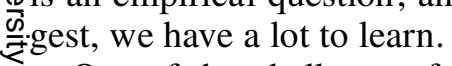

One of the challenges for local improvisation is visibility. On the one hand, local, everyday forms of innoJैvation tend to be missing from official accounts of ICT @i development and implementation. The project for us as $\underset{\mathbb{\Phi}}{\mathrm{C}}$ researchers in that respect is to bring this form of what soPciologists Anselm Strauss and Susan Leigh Star (Strauss \&\& Star, 1999; Strauss, 1985) have named "invisible work" ठ̈into the light. On the other hand, invisibility affords cercotain spaces for actions that, rather than being celebrated gonce the light is shone on them, may rather be threatened D. ₹which I am familiar large, highly visible change agendas Omay actually create incentives to keep local innovations Vhidden (see Suchman \& Bishop, 2000). Insofar as the latter are dependent on particular social relations and ways of working, their appropriation into global initiative s runs the risk of destroying the very conditions that make the local innovation s possible. I come back to this later.

The problem of invisible work brings us to the third theme; namely, work practices, or the particular forms of labor that make up the production and use of information technologies wherever they occur. Here a central issue is how we should understand the relation between existing practices and projects of new technology and organizational design. Fundamental to this project is to move beyond the "fallacy of the empty vessel" (Jordan, 1997; Suchman \& Jordan, 1988) - that is, the assumption by those who position themselves at the center of some form of knowledge production that there is no knowledge anywhere else, but only empty receptacles waiting to be filled. In other words, to put it bluntly, mistaking one's own ignorance of what exists elsewhere-knowledges, information systems, practices-for their absence.

In what follows I take up these themes in a domain with which I am familiar: that is, the area of ICT research and development $(R \& D)$ as practiced in large companies in the United States. My aim is twofold. First, I hope to engage in some demystification of prevailing $R \& D$ practice, to dispel any illusion that everything works smoothly somewhere else, as well as to report on what one approach to an alternative practice looks like in the contexts that I know. Second, in asking the question of what kinds of troubles arise in the contexts that I know and why, I hope to identify what I suspect are some common issues in relations between ICT production and use across locations. By talking about these things from my own experience, while trying to draw out of that experience some more general lessons, I hope to contribute some suggestive starting places for a discussion of the particular problems and possibilitie s that ICT designers and users in the developing countries must face, and the kinds of strategies that are emerging to deal with them.

My own work has involved a series of projects that have placed me increasingly inside the worlds of professionalized technology production, from the particular (if not peculiar) point of view of research and development in a "Fortune 500" company in the United States. A recurring question for me as a participant in discussions on design in these contexts is, "Who is doing what to whom here?" Within prevailing discourses, anonymous and unlocatable designers, with a license afforded by their professional training, problematize the world in such a way as to make themselves indispensable to it and then discuss their obligation to intervene, in order to deliver technologi cal solution s to equally decontextualize $d$ and consequently unlocatable "users." This stance of design from nowhere is closely tied to the goal of construing technical systems as commodities that can be stabilized and cut loose from the sites of their production long enough to be exported en masse to the sites of their use. As Hales observed, "In a sense, the very purpose of commodity markets is to secure objective economic connection with a minimum of cultural (communicative) connection" (1994, p. 14).

In reaction to this situation I have found myself increasingly preoccupied with locations and boundaries, specifically with efforts to identify them, understand them, and ultimately redraw them. The first are those closest to home, between the various networks that make up the multinational corporation in which I worked for 20 years. Within the company's United States operations alone there exist multiple social worlds differentiated by geographical, organizational and professional locations. My own position within the corporation was defined in relation to these worlds and by an additional set of working relationships which was perhaps the most important. That was a small network of allies including anthropologists, computer scientists, engineers, and product designers distributed among several sites within the United States and England. What bound us together were a series of 
dissatisfaction s regarding the regime within which we were asked to work, and a set of partial but related visions for how things might be different.

As members of a very large enterprise engaged in the production of new technologies, my colleague s and I found ourselves enmeshed in an overwhelmingly complex network of relations, for the most part made up of others whom we had never met and of whose work we were only dimly aware. Within industrial research the distinctions are primarily disciplinary: Computer science, electrical engineering, mathematics, cognitive psychology, linguistics, and anthropology all orient not only to different \% problems but more significantly to different, sometimes inष्Q commensurate conceptions of the social/technical world. WAnd as researchers we are all defined in contradistinction $\stackrel{\sim}{r}$ to enterprises of product design, development, manufacturing, and finance, strategic planning, human resource management, marketing, and sales and service, each of $\stackrel{\infty}{\rightleftharpoons}$ which in turn is itself a complex social world comprising distinctive identities, concerns, accountabilities, and $\overrightarrow{5}$ working practices.

Our dissatisfactions and visions were related to a furकी ther set of boundaries as well, drawn between professional Ф Pspecifically, as researchers and developers we found ourOselves cut off from prospective technology users at the ळेsame time that our enterprise was legitimized by them. A cocrucial assumption underwriting these boundaries is the ळp premise that technical expertise is not only a necessary, D but is the sufficient form of knowledge for the production ₹ of new technologies.

O One of my concerns has been that this simple $\checkmark$ designer/user distinction obscures the realities of system development in two ways. First, it draws as unambiguous what is in practice a highly shifting and perspectival boundary, missing the ways in which professional designers are themselves among the most intensive of technology users on the one hand, and making invisible the multiple forms of vernacular design-in-us e on the other. At the same time, the simple dualis $m$ closes off our possibilitie s for recognizing the many subtle and profound differences that actually do divide us, and for replacing the designer/user opposition with a rich, densely structured landscape of identities and working relations, within which we might begin to move with some awareness and clarity of our various positions.

Traditionally, the relations among disparate activities of technology production have been viewed as a series of hand-offs along a kind of multidisciplinary assembly line. On this premise, for example, the role of research is to construct the technological foundations on top of which future devices will be built, including visions of how the future will be. A longstanding mutual dissatisfaction between research and product development arises from the failure of technologies and ideas to "transfer" from one to the other, understood by one side as a failure of development to take advantage of the results of research, and by the other as a failure of research to address the needs of development.

My own experience of this gap began in the early 1980 s in grappling with the question of how an anthropology of technology might be made relevant to the design of machine interfaces. The first proposal was that, as ethnographers, we might serve as intermediaries between users and designers. Increasingly, however, our reluctance to translate our practice directly into design terms was met with frustrations from the product development community. Our hesitation to produce such translations led to our characterization as recalcitrant social scientists, unwilling to roll up our sleeves and engage in the real work of design. For a time I at least was confused by this, feeling that to deliver design implications was indeed my responsibility but that I was unable to do so. I dwelled uncomfortably for several years within this gap between my practice and that of my design coworkers, seeing it not as a systemic discontinuity but as a personal shortcoming.

Gradually, however, we came to see that the problem lay neither in ourselves nor in our colleagues, but in the prevailing division of professional labor and the assumptions about knowledge production that lay behind it. The discontinuitie s across our intellectual and professional locations meant that we could not simply produce "results" that could be handed off to our colleagues. What we were learning was inseparably tied to the ongoing development of our own theorizing and practice, such that it could not be cut loose and exported elsewhere. Rather than feeling inadequate in the face of demands that our work produce design implications, we began to resist those demands. We resisted them not on grounds of scientific "purity" or by denying our responsibility for design, but by rejecting assumptions on the basis of which the demands for our knowledge were being made. In place of the model of knowledge as a product that can be assembled through hand-offs in some neutral or universal language, we began to argue the need for mutual learning and partial translations.

At the same time, we began to find allies within the design community itself. Within the corporation, our colleagues who had spent much of their professional lives designing control panels for discrete "stand-alone boxes" now were being told by their management to envision a future of devices that would be tied together through networks, with the functionality of the overall system distributed dynamically among them. Increasingly, our colleagues were finding that their traditional methods for generating design ideas (focus groups, usability tests) were ineffective. Motivated first on our part by economic necessity 
(in particular, the necessity of obtaining support from the product organization for our anthropological research projects ) and then increasingly by genuine affinity, a small network of working relations grew up across the divide. Together, we realized, we might actually be able to bring our respective knowledges to bear on the shared problem of how to develop new practices of technology design.

Our attempts to develop those practices involved projects intended deliberately to cut across the organizational boundaries that separated us, both from each other oas design professionals within the corporation and from the potential users of the technologies we were designing. The goal of the projects was to develop a work-oriented Q $d$ design practice that engaged members of a specific site wof potential technology use as collaborators in technology - production. The project, in other words, became one of asserting the relevance of other knowledges - particularly \$knowledge of relevant work practices-for system design.

$\stackrel{\vec{D}}{\gtrless}$ For inspiration we turned to other parts of the indusotrialized world, in particular to Scandinavia. A premise of ${ }_{5}$ Scandinavian participatory design is that there is in fact no Distinct boundary between technology design and use, inSofar as professional designers, in order to develop systems $\stackrel{\Phi}{\subseteq}$ with any integrity, must develop them in relation to specific Psettings of use. Correspondingly, if technologies are to be Omade useful, practitioners of other forms of work must \&effectively take up the work of design. Integration, local coconfiguration, customization, maintenance, and redesign פon this view represent not discrete phases in some "sysD. tem life cycle" but complex, densely structure d courses of ₹articulation work, without clearly distinguishable boundOaries between them.

The difficulty with this project is that the boundaries that currently define relations of professional design and use are realized through institutionalize $d$ arrangements that are organized systematically to reproduce them. In those cases where boundary crossings do occur, moreover, we discover that crossing boundaries involves encountering difference, entering onto territory in which one is a stranger and, to some significant extent therefore, unqualified. For those who have spent a lifetime building up their competence within a domain of specialized professional practice, deliberately placing oneself on unfamiliar ground is a difficult thing to do.

To further this process requires that system developers become responsible for locating themselves within the extended networks of social relations and forms of work that constitute technical systems. That is not to say that they can in any strong sense control those networks. On the contrary, a primary implication of this view is that developers must give up control over technology design (which is in any case illusory), and see themselves instead as entering into an extended set of working relations, of contests and alliances. The question at each next turn becomes: How do we proceed in a responsible way? To answer this question requires analyzing the processes by which boundaries are constructed and maintained, and understanding our contribution s to their reproduction or transformation. And it means mapping not only our local networks, but locating those as well within more extended networks, including an increasingly globalized division of labor.

As design work becomes located, however, we begin to replace what Haraway described as "ways of being nowhere while claiming to see comprehensively" or "the god trick" (1991, p. 193), with "views from somewhere" (p. 196). This repositioning, which I have called located accountability (Suchman, 1994), is built on what Haraway termed "partial, locatable, critical knowledges" (1991, p. 191). As Haraway made clear, the fact that our knowing is relative to and limited by our locations does not in any sense relieve us of responsibility for it. On the contrary, it is precisely the fact that our vision of the world is a vision from somewhere-that it is based in an embodied, and therefore partial, perspective- that makes us personally responsible for it. The only possibility for the creation of effective technologies, from this perspective, is through collective awareness of the particular and multiple locations of their production and use.

But again, to realize this vision is extremely difficult. One of the things that makes it so is the phenomenon that Brigitte Jordan has named authoritative knowledge (Suchman \& Jordan, 1988; Davis-Floyd \& Fishel Sargent, 1997). Authoritative knowledge refers to those ways of knowing that are taken to be legitimate, consequential, worthy of discussion, and useful for justifying actions by people engaged in accomplishing some concerted task. As it turns out, there is an intimate relationship between the materialities of human activity - settings, artifacts, and technologies - and the politic s of authoritative knowledge. Technological change can therefore be an occasion for either the expansion of existing forms of authoritative knowledge, or for their transformation. To illustrate this point, we undertook a comparative analysis of two seemingly unrelated forms of activity - childbirth and office work (Suchman \& Jordan, 1988). Our argument was that in both cases ideological assumptions about who holds relevant knowledges override the realities of what, in this case, particular women know, and dictate a model of the activity that, when embodied in technologies, enforces those assumptions.

We drew several lessons from these cases:

1. Regimes of authoritative knowledge rely upon culturally constructed, generally differential valuations of knowing and acting.

2. There is a politics of technology that comes from the intimate relation of ownership and control of technology to distribution s of authoritative knowledge. 
3. Technologies designed at a distance generally are characterized by a design/use gap that requires either substantial reworking of the technology or, if that is impossible and prospective users are powerful enough, its rejection.

4. Technological innovation can be a resource either for the preservation of existing ideologies and associated distribution s of symbolic and material reward, or for their transformation.

A recurring theme in the articles collected here is the need for strategies that move marginalized voices and ways of knowing into the center of relevant commercial, govern\$ $m e n t a l$, and public discussion of information and informaWotion technologies. At the core of this project is the question nnot only of how information flows, but of who defines what constitutes "information" in the first place. What forms of knowing are recognized, by whom, and with what con$\stackrel{\infty}{\rightleftharpoons}$ sequence? One of the characteristics of the site within owhich I have been working is its construction as central $\vec{s}$ to the production of new information technologies. I am 今onterested in the everyday practices through which that "centrality" is produced and maintained. A key element $\underset{\Phi}{\Phi}$ is the privileging of certain restricted ways of knowing Pand networks of knowledge production, and an associated Oparochialism that keeps other ways of knowing at a disठ̈tance. This is of course an age-old strategy of colonial opowers, and it is in part where the figure of the anthropol@ogist like myself comes into the picture.

Ethnography began, after all, as an enterprise funded by, and in the service of, certain powerful actors interested Oin managing others. In anthropology's early days, in the last century, the powerful actors were colonial administrators, the relevant others the so-called native peoples who inhabited the colonies and provided the work force for, or alternatively, the sources of resistance to, imperialist enterprises. Early anthropologist s went out to the colonies on the premise that theirs was a project of objective recording, aimed at bringing back knowledge of native peoples that would be useful in colonial design and administration . Over the years, in part in reaction to this early history, anthropology and ethnography have taken a different turn. Critical discussions and revisions of ethnography within the field have transformed ethnography from an objectivis $t$ enterprise in the service of colonialis $m$ to a sometimes militant source of radical intervention s and critique on the part of postcolonial efforts (see for example Marcus \& Fischer, 1986; Escobar, 1994; Gupta \& Ferguson, 1997).

With the incorporation of anthropology into now early21 st-century capitalism, the colonial beginnings of the discipline are overlaid with new commercial projects. The relevant Other has become the user or, more recently, the consumer, whose needs and desires (or "experiences") the anthropologist is charged with capturing and bringing home to her commercial employer. The questions of what happens after colonialis $m$ that animated anthropolog y late in the last century have not gone away, but they have been reconfigured and overlaid with new questions of, among other things, whose voices travel over the circuits laid down by what forms of information and communication technologies, and with what effects.

Libby Bishop and I have compared our experiences of what innovation looks like in the setting $\mathrm{s}$ with which we are familiar (Suchman \& Bishop, 2000). Our observations of new technology, work redesign, and organizational change initiative s indicate that "innovation" in these contexts requires analysis not simply as a process that takes place (or does not), but as a highly politicized construct taken up by specific actors and made to work in particular ways. At least within the United States, and to some extent within Western economies more generally, innovation is accepted without question to be a positive good. In a semiotics of bipolarized, differently valued opposites, "innovation" is the preferred alternative to "stagnation" or "resistance to change." This means that framing agendas under the rubric of innovation and change is inevitably a strategic move, appropriating the positive value of the term for whatever the agenda to be pursued in its name might involve.

In contrast, our experience suggests that like new technologies, change agendas may actually be directed at least as much at the reproduction of existing organizational and economic orders as at their transformation. This is the case insofar as corporate innovation initiative s are aimed in practice at the intensification of ongoing activities within an existing market with the object of increasing returns on the conduct of business-as-usual. Alternatively, innovation projects are often concerned with the extension of existing activities into additional and/or different markets. In both cases, "innovation" can be understood as a construct activated in the service of what is, on closer inspection, a fundamentally conservative (in the sense of the reproduction of existing orders) project.

At the same time, our experience and observation s point toward some alternate understanding s of change and innovation in the workplace. This alternate view rests on the premise that innovation and change are indigenou s aspects of technologies-in-use, work practice, and organizational life. Even to keep things going on "in the same way" in practice requires continuous, mundane forms of active appropriation and adaptation of available resourcesdiscursive and material-to the circumstances at hand. This stands in contrast to the view of organization members as intrinsically conservative, simply reproducing the status quo until some professional designer or organizational change agent comes along to insist that things be different.

Second, sustainable innovation s are dependent on substantial investments of time and resources in infrastructure 
development. By "infrastructure" in this context we mean to include a range of social relations and material arrangements. Social relations develop only with time, and material arrangements require human labor to put them in place and keep them going. This means that innovation and change are inevitably costly undertakings, and require associated commitments to their ongoing, long-term development.

Third, innovation is less a question of singular inventions or wholesale transformations than a matter of what OI have described as artful integrations (Suchman, 1994). The premium placed on discrete, discontinuous change Devents, and the generally negative value attributed to pro§cesses of "incremental" change, are part of a form of Wowishful thinking that aims to bring about desired transformations without the associated costs in time and human Seffort. In contrast, a frame of artful integration emphasizes ळthe ways in which new things are made up out of reconfigurations and extensions to familiar environments and forms of action. While less available for ownership by individual $\vec{D}$ "change agents," innovation of this latter kind, we propose, Whas deeper roots and is more likely to produce change of @़ lasting value.

Ф Resistance to change is commonly cited in the "develPoped" world as a characteristic of organization members gor, in the "developing" world, as a characteristic of indige ठ̊nnous peoples, arising from their (largely irrational) attachcoment to the status quo. In contrast, we might view the term ¿्و "change" as one useful tool for an agenda concerned with D. ₹symbolic and material reward remain the same. We are Othen left to find alternative readings of "resistance" and "change," understood as reasonable responses to actual shifts in the technological and organizational landscape. One implication of this alternate view of innovation is that resistance to change, in the sense of resistance to the premises and consequences of agendas initiate $d$ under that banner, may in some cases be a requirement for long-term, substantive innovation.

The frame of information systems research and development that I hope to have outlined here is built around a deepening awareness of the work required to achieve technology stabilization, and one's location within the extended network of working relations that makes technical systems possible. To achieve this awareness, our research needs to work across the grain of received categories and distinction s to recover the specific social, material, politi- cal, and economic realities that those categories both reveal and obscure. The project also involves redrawing boundaries and lines of interaction in such a way that identities of technology designer and user, and the relations between them, are transformed. And as those in South Africa can appreciate perhaps better than anyone, this implies that our intervention s in identities and relations of technology production are part of a larger enterprise of disrupting and remaking the social world.

\section{REFERENCES}

Davis-Floyd, R., and Fishel Sargent, C., eds. 1997. Childbirth and authoritative knowledge: Cross-cultural perspectives. Berkeley, CA: University of California Press.

Escobar, A. 1994. Encountering development: The making and unmaking of the Third World. Princeton, NJ: Princeton University Press.

Gupta, A., and Ferguson, J. 1997. Anthropological locations. Berkeley: University of California Press.

Hales, M. 1994. Where are designers? Styles of design practice, objects of design and views of users in computer-supported cooperative work. In Design issues in CSCW, eds. D. Rosenberg and C. Hutchison, pp. 151-177. Dusseldorf: Springer Verlag.

Haraway, D. 1991. A cyborg manifesto: Science, technology, and socialist-feminism in the late twentieth century. In simians, cyborgs and women, pp. 149-181. New York: Routledge.

Jordan, 1997. Authoritative knowledge and its construction. In Childbirth and authoritative knowledge: Cross-cultural perspectives, eds. R. Davis-Floyd and C. Sargent, pp. 55-79.

Marcus, G., and Fischer, M. 1986. Anthropology as cultural critique. Chicago: University of Chicago Press.

Miller, D., and Slater, D. 2000. The Internet: An ethnographic approach. Oxford: Berg.

Star, S. L., and Strauss, A. 1999. Layers of silence, arenas of voice: The ecology of visible and invisible work. Computer-Supported Cooperative Work 8:9-30.

Strauss, A. 1985. Work and the division of labor. Sociological Quarterly 26:1-19.

Suchman, L. 1994. Working relations of technology production and use. Computer Supported Cooperative Work 2:21-39.

Suchman, L., and Bishop, L. 2000. Problematizing "innovation" as a critical problem. Technology and Strategic Management 12(1):327333.

Suchman, L., and Jordan, B. 1988. Computerization and women's knowledge. In Women, work and computerization: Forming new alliances, K. Tijdens, M. Jennings, I. Wagner, and M. Weggelaar, eds. pp. 153-160. Amsterdam: North Holland. Reprinted in P. Agre and D. Schuler, eds. (1997), Reinventing technology, rediscovering community: Critical explorations in computing as a social practice, pp. 97-105. Greenwich, CT: Ablex. 